Jpn. J. Genet. (1989) 64, pp. 373-382

\title{
Multifactorial sex determination in natural populations of the housefly (Musca domestica) in Japan
}

\author{
Takashi ToMITA and Yoshihito WADA* \\ Department of Medical Entomology, National Institute of Health \\ Kamiohsaki 2-10-35, Shinagawa-ku, Tokyo 141
}

(Received 21 August 1989)

\begin{abstract}
Geographic variation in sex-determining factors was studied in 19 localities in Japan between 1981 and 1986. The association of the male-determining factor, $M$, was demonstrated with all linkage groups, and the most predominant carrier of the $M$ in each locality was either the $\mathrm{III}^{\mathrm{M}}$ or the $Y$ chromosome. The fraction of $Y$ in $M$-carrying chromosomes was higher in Hokkaido, and declined significantly on moving to the south. The frequency of the females carrying the female-determining factor, $F$, which is epistatic to the $M$ factor, was sporadically distributed in the populations surveyed. However, male heterogamety was largely retained in the populations in Hokkaido. We present a hypothesis that broadly ranging geographic variation in sex-determining factors reflects a transient state caused by recent invasions of autosomal sex-determining factors. No significant difference in the index combined with segregation rate of the $M$ carrying gamete and viability was indicated between the males of $X / Y$ and III $^{\mathrm{M}} / \mathrm{III}$.
\end{abstract}

\section{INTRODUCTION}

The sexual development of the housefly, Musca domestica, is determined by the presence or the absence of an epistatic sex factor. The $Y$ chromosome has been proven to be the carrier of a male-determining factor, $M$, while the $X$ chromosome plays no role in sex determination (Hiroyoshi, 1964; Rubini and Palenzona, 1967). Male heterogamety by female $X X$ and male $Y Y$ was previously believed to occur in the housefly by examining flies which were probably of European origin (Stevens, 1908; Metz, 1916; Keuneke, 1924; Perje, 1948). Identificantion of autosomal sex-determining factors in several parts of the world has shown that no simple mechanism of sex determination can be applied to recent natural populations. The $M$ factor has been demonstrated in all the autosomal linkage groups (reviewed in Tsukamoto et al., 1980; Franco et al., 1982; Inoue and Hiroyoshi, 1984; Inoue et al., 1986). The autosome carrying $M$ is here generally termed $\mathrm{A}^{\mathrm{M}}$ or individidually $\mathrm{I}^{\mathrm{M}}, \mathrm{II}^{\mathrm{M}}, \cdots$, or $\mathrm{V}^{\mathrm{M}}$. The number with superscript $\mathrm{M}$ indicates

\footnotetext{
* Present address: Department of Medical Entomology, Institute of Tropical Medicine, Nagasaki
} University, Sakamoto-machi, Nagasaki 852 
the corresponding autosomal number. Every single $A^{\mathrm{M}}$ is equivalent to the $Y$ chromosome as a male determinant. The female-determining factor, $F$, which is located on autosome 4, causes the fly carrying the $M$ factor(s) to develop into a fertile female (Rubini, 1967; Wagoner, 1969; McDonald et al., 1978; Inoue and Hiroyoshi, 1982). Thus the necessary and sufficient condition to be a male is both the presence of at least one $M$ factor and the absence of $F$ factor in the genome, and that to be a female is the logically opposite situation.

The genetical study of the housefly started in the 1950's. Some pioneering researchers have hypothesized that autosomal $M$ and $F$ factors are recent invaders and are supplanting the ancestral $X-Y$ mechanism (Hiroyoshi and Fukumori, 1977, 1978; Tsukamoto et al., 1980; Franco et al., 1982; Denholm et al., 1985). The basis for the hypothesis has come partly from distinctive geographical variations in sex determinants. The fly populations in continental Europe showed a clinal transition in male determinants from wholly $\mathrm{A}^{\mathrm{M}}$ at low altitudes in the south to wholly $Y$ in the north (Franco et al., 1982). Populations in the British Isles showed a radial distribution of the $F$-carrying female $(F /+)$, which was predominant in southeast England and gradually decreased with distance from this region (Denholm et al., 1985).

We report here on the geographic variation in the fraction of each $\mathrm{A}^{\mathrm{M}}$ and $Y$ chromosome and the frequency of $F /+$ females in the fly populations in Japan, based on individually estimated genotypes. Then, we discuss whether the sexdetermining system is in a transient state, taking into consideration the differences between the present result and the data obtained 25 years ago (Hiroyoshi, 1964), and the data obtained from a geographic survey of an isozyme polymorphism (Agatsuma and Takeuchi, 1978).

\section{MATERIALS AND METHODS}

\section{Populations}

Flies were collected from 1981 to 1986 at 19 localities of livestock-breeding farms and dumping spots that were distributed from Hokkaido to Okinawa, from north to south in Japan. The name of localities and the collecting years re presented in Table 1, and the geographic distribution of the localities is shown in Fig. 1.

\section{Male genotype with $M$ factor}

Collected males were analyzed by the backcross method using females of the mutant strain, $a c ; a r ; b w b ; y e ; s n p$, each autosome of which was marked with a recessive visible trait (Tomita and Hiroyoshi, in preparation). By this method, individual male genotypes can be estimated, being specified for all the possible linkage relationships and homo/heterozygostity of the $M$ factor. 


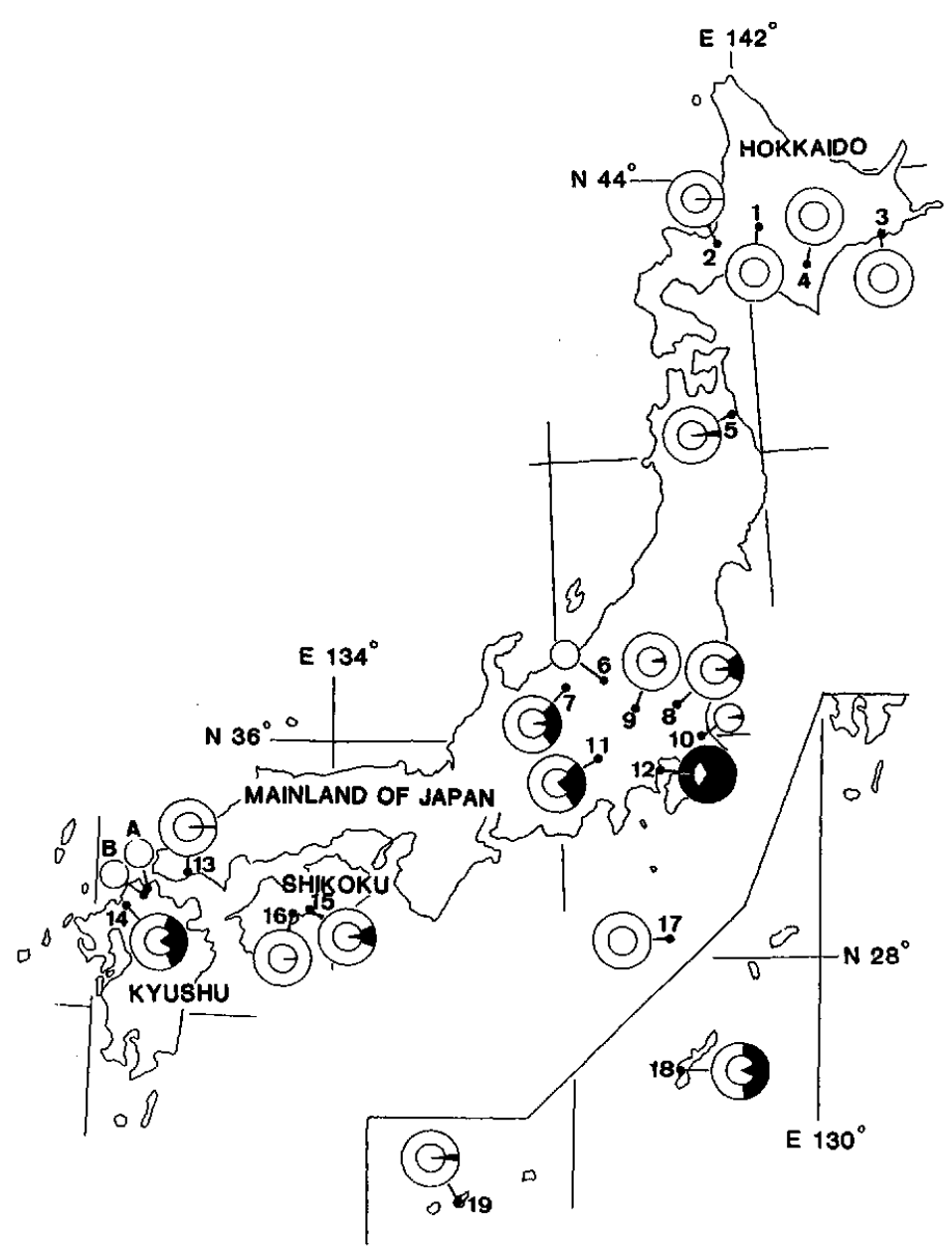

Fig. 1. Geographic distribution of the frequencies of the $F /+$ female and the male carrying plural $M$ factors. Black areas in large and small circles indicate the frequencies of the $F /+$ female and the male carrying plural $M$ factors, respectively. The code number corresponds to that with each locality name in Table 1. "A" and "B" denote Wakamatsu and Ohira in Kitakyushu, respectively. The data for these localities were taken from Tsukamoto et al. (1980).

Female genotype with $F$ factor

Collected females were allowed to oviposit individually. In the next generation, a female progeny extracted singly from each line was mated to a male homozygous with the $M$ facotr. The genotype of a sampled femäle, either $F /+$ or $+1+$, was recognized by the presence or the absence of the female progeny. 


\section{RESULTS}

\section{Male-determining factors}

The male genotype with the $M$ factor was examined in 19 samples. All sorts of $\mathrm{A}^{\mathrm{M}}$ chromosome and $Y$ chromosome were isolated from the total populations. The fraction of each $\mathrm{A}^{\mathrm{M}}$ or $Y$ among $M$-carrying chromosomes is presented in Table 1. The predominant carrier of the $M$ in each sample was III $^{M}$ or $Y$. Latitudinal distribution of the fractions of $I I^{M}$ and $Y$ is shown in Fig. 2, in which the results on two samples of Kitakyushu (Tsukamoto et al., 1980) are included. Both III $^{\mathrm{M}}$ and $Y$ were detected in all samples, except for those from Kitakyushu and Hachijo, which contained only the $\mathrm{III}^{\mathrm{M}}$ chromosome. The fraction of $Y$ was consistently high in 4 samples from Hokkaido (0.70-0.91), but was low in samples from the mainland, Shikoku and Kyushu (0.0-0.70, including Kitakyushu), and was very low in samples from the 3 southern islands $(0.0-0.14)$.

A total of 21 samples were tested for regression of the fraction of $Y$ on latitude by the analysis of variance. The results indicated a significant north-south cline

Table 1. Fraction of each $M$ factor-carrying chromosome and frequency of the $F /+$ female in samples from 19 localities

\begin{tabular}{|c|c|c|c|c|c|c|c|c|c|c|c|c|}
\hline \multirow[b]{2}{*}{$\begin{array}{c}\text { Code } \\
\text { no. }\end{array}$} & \multirow{2}{*}{ Location } & \multirow{2}{*}{ Year } & \multirow{2}{*}{$\begin{array}{l}\text { No. of } \\
\text { males } \\
\text { tested }\end{array}$} & \multicolumn{6}{|c|}{ Fraction of $M$-carrying chromosome } & \multirow{2}{*}{$\begin{array}{c}\text { Freq. of } \\
\text { males } \\
\text { carrying } \\
\text { plural } \\
M \mathrm{~s}\end{array}$} & \multirow{2}{*}{$\begin{array}{l}\text { No. of } \\
\text { females } \\
\text { tested }\end{array}$} & \multirow{2}{*}{$\begin{array}{l}\text { Freq. of } \\
F /+ \\
\text { females }\end{array}$} \\
\hline & & & & $I^{M}$ & $\mathrm{II}^{\mathrm{M}}$ & $\mathrm{III}^{\mathrm{M}}$ & $\mathrm{IV}^{\mathrm{M}}$ & $\mathrm{V}^{\mathrm{M}}$ & $Y$ & & & \\
\hline 1 & Furano & '83 & 79 & 0.0 & 0.0 & 0.009 & 0.0 & 0.0 & 0.91 & 0.0 & 6 & 0.0 \\
\hline 2 & Sapporo* & '84 & 302 & 0.0 & 0.0 & 0.292 & 0.0 & 0.006 & 0.702 & 0.003 & 171 & 0.006 \\
\hline 3 & Akkeshi & '83 & 33 & 0.0 & 0.0 & 0.21 & 0.0 & 0.0 & 0.79 & 0.0 & 28 & 0.0 \\
\hline 4 & Obihiro & '83 & 49 & 0.0 & 0.0 & 0.12 & 0.0 & 0.0 & 0.88 & 0.0 & 13 & 0.0 \\
\hline 5 & Hachinohe & '82 & 57 & 0.0 & 0.0 & 0.38 & 0.0 & 0.005 & 0.57 & 0.02 & 56 & 0.04 \\
\hline 6 & Niharu & '82 & 22 & 0.05 & 0.0 & 0.32 & 0.0 & 0.0 & 0.64 & 0.0 & - & - \\
\hline 7 & Togakushi & '83 & 25 & 0.0 & 0.08 & 0.58 & 0.0 & 0.0 & 0.35 & 0.04 & 25 & 0.28 \\
\hline 8 & Haga & '86 & 52 & 0.0 & 0.02 & 0.96 & 0.0 & 0.0 & 0.02 & 0.04 & 30 & 0.17 \\
\hline $\mathbf{g}$ & Miyagi & '86 & 38 & 0.0 & 0.03 & 0.35 & 0.0 & 0.0 & 0.63 & 0.05 & 30 & 0.0 \\
\hline 10 & Hokota & '82 & 42 & 0.0 & 0.02 & 0.57 & 0.0 & 0.0 & 0.40 & 0.05 & - & - \\
\hline 11 & Kofu & '83 & 25 & 0.0 & 0.0 & 0.70 & 0.0 & 0.0 & 0.30 & 0.24 & 41 & 0.29 \\
\hline 12 & Yumenoshima & 91 & 40 & 0.0 & 0.01 & 0.74 & 0.0 & 0.0 & 0.25 & 0.68 & 87 & 0.99 \\
\hline 13 & Aio & '84 & 57 & 0.02 & 0.31 & 0.29 & 0.03 & 0.22 & 0.12 & 0.02 & 92 & 0.01 \\
\hline 14 & Kasuya & '84 & 97 & 0.01 & 0.16 & 0.39 & 0.0 & 0.18 & 0.26 & 0.20 & 39 & 0.38 \\
\hline 15 & Nangoku & 82 & 31 & 0.03 & 0.0 & 0.24 & 0.0 & 0.03 & 0.70 & 0.06 & 16 & 0.13 \\
\hline 16 & Haruno & '84 & 61 & 0.0 & 0.0 & 0.34 & 0.0 & 0.0 & 0.66 & 0.02 & 27 & 0.0 \\
\hline 17 & Hachijo & $' 82$ & 28 & 0.0 & 0.0 & 1.0 & 0.0 & 0.0 & 0.0 & 0.00 & 16 & 0.0 \\
\hline 18 & Okinawa & '84 & 40 & 0.04 & 0.41 & 0.48 & 0.02 & 0.0 & 0.04 & 0.15 & 17 & 0.47 \\
\hline 19 & Ishigaki & '84 & 49 & 0.0 & 0.32 & 0.54 & 0.0 & 0.0 & 0.14 & 0.02 & 45 & 0.04 \\
\hline
\end{tabular}

* Results of the 6 localities in and around Sapporo were combined. 


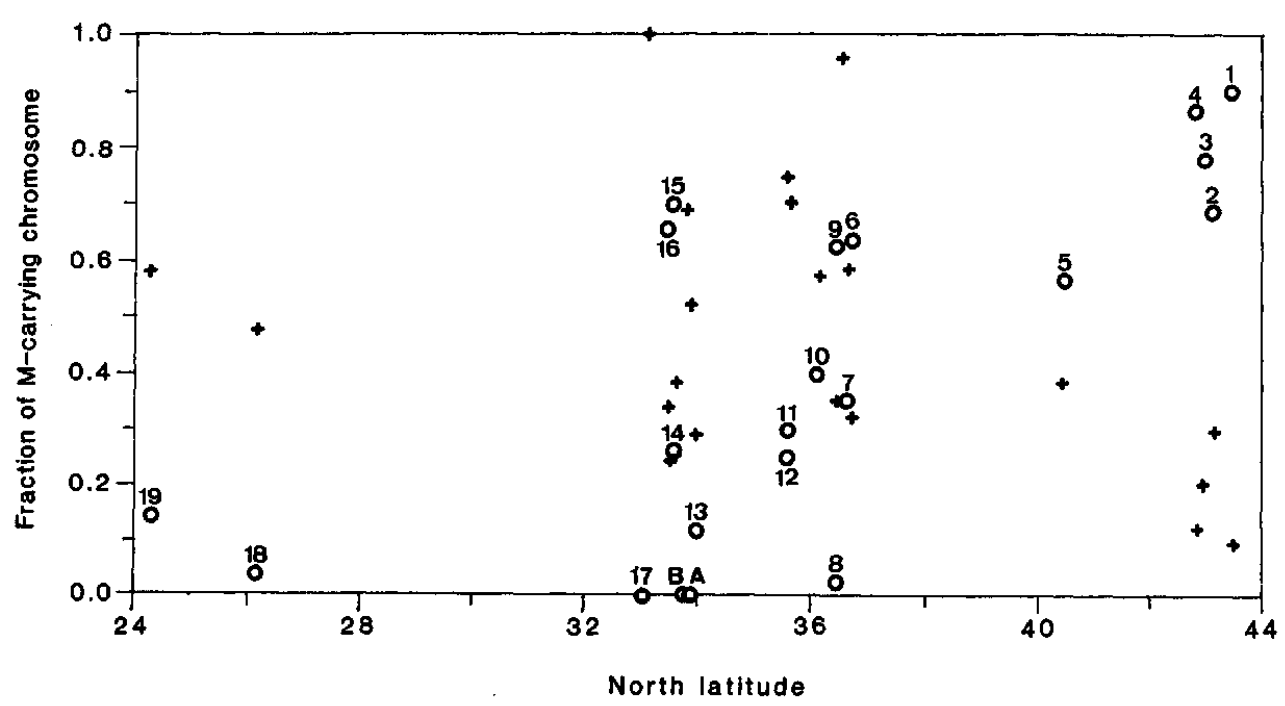

Fig. 2. Latitudinal distribution of the fractions of the $Y$ and the $\mathrm{III}^{\mathrm{M}}$ chromosomes among $M$ factor-carrying chromosomes. Circle and cross represent $Y$ and $\mathrm{III}^{\mathrm{M}}$, respectively. The code number corresponds to that with each locality name in Table 1. " $A$ " and " $B$ " denote Wakamatsu and Ohira in Kitakyushu, respectively, and were taken from Tsukamoto et al. (1980).

$\left(\mathrm{F}_{1,19}=17.8, \alpha<0.01\right)$. Geographic distribution of the fraction of $\mathrm{III}^{\mathrm{M}}$ showed a reversed pattern to than of $Y$, though the latitudinal cline in this case was not significant (data not shown). The other $\mathrm{A}^{\mathrm{M}}$ chromosomes, $\mathrm{I}^{\mathrm{M}}, \mathrm{II}^{\mathrm{M}}, \mathrm{IV}^{\mathrm{M}}$, and $\mathrm{V}^{\mathrm{M}}$, were less frequent than $Y$ or III $^{M}$ in many samples except for ${ }^{M} I^{M}$, which was the most or next predominant in the samples from Aio, Okinawa and Ishigaki. In four samples from Hokkaido (code no. 1-4 in Table 1), the only $\mathrm{A}^{\mathrm{M}}$ chromosome isolated in addition to $\mathrm{III}^{\mathrm{M}}$ was the $\mathrm{V}^{\mathrm{M}}$ chromosome in the samples from Sapporo.

On the contrary, there was a much variety in the linkage relationships of $M$; this was characteristic of the southwest part of Japan. The greatest variety in $M$-carrying chromosomes was shown in samples of the southern localities, Aio, Kasuya and Okinawa (Table 1). The $\mathrm{IV}^{\mathrm{M}}$, which had been the only unidentified $\mathrm{A}^{\mathrm{M}}$, was also included in the samples of Aio and Okinawa as a minor carrier of the $M$, though genetic mapping of the $M$ on this chromosome was reported earlier (Inoue et al., 1986).

\section{Female-determining factor}

The female genotype with or without the $F$ factor, either $F /+$ or $+/+$, was examined in 17 samples. Frequencies of the $F /+$ female and their latitudinal distribution are shown in Table 1 and Fig. 1 . The $F /+$ female was either not detected or very rare $(0.0-0.006)$ in the 4 samples from Hokkaido, while the frequency ranged broadly $(0.0-0.99)$ in the 13 samples from the mainland and 
southern districts of Japan. Among the latter, the results from Yumenoshima, Okinawa, Kasuya and Kofu showed the highest values, $0.99,0.47,0.38$ and 0.29 , respectively. Since the presence of $F$ in a population causes the male to be homozygous or multiply heterozygous with $M$, the ferequency of the $F /+$ female is thought to positively correlate to the frequency of the male carrying plural $M$ factors. This frequency is also shown in Table 1 and Fig. 1.

The male frequencies in the above 4 samples also had higher values, $0.68,0.15$, 0.20 and 0.24 , respectively (Table 1). Although females were not directly examined in the two samples from Niharu and Hokota, all males examined carried a single $M$ factor; this result indicates the absence or a very low frequency of the $F$ in these localities. Similar results were proviously obtained in the 2 samples from Kitakyushu (Tsukamoto et al., 1980). Yumenoshima, Okinawa and Kasuya are closely located to Hokota, Ishigaki and Kitakyushu, respectively. The frequencies of the $F /+$ female in the former 3 samples gave the first to third highest values, whereas those in the latter three samples were directly or indirectly estimated to be very low, if present at all. Thus no simple clinal pattern could be demonstrated in the samples examined. The frequency of the $F /+$ female seems to distribute sporadically in the natural populations in the mainland and southern parts of Japan.

Sex-determining system in Yumenoshima population

Several complicated male genotypes with $M$ appeared in the Yumenoshima samples as a genetic consequence of an extremely high frequency of the $F /+$ female and coexistence of several $M$ carriers (Table 1). The male genotypes are shown with their observed numbers in Table 2. All of the 40 males examined carried at least one $\mathrm{III}^{\mathrm{M}}$ chromosome, and among them, 27 were the carrier of two or more $M$ factors. Such complicated male genotypes as triple heterozygotes or double homozygotes were also included in the samples. The average dose of the $M$ factor in male genome was 2.0, which is twice as much as that in the males in the population without $F$. Both the values of 2.0 in this male index and 0.99 in the $F /+$ female frequency represent the population approaching a female heterogametic sex-determining system.

Sex ratios in the $F_{1}$ progeny from the mating of sex factor free females with III ${ }^{M} / I I I$ and $X / Y$ males

In the process of estimating male-determining genotypes, collected males were individually mated to females of the $a c$; $a r ; b w b ; y e ; s n p$ strain. Then, the sex ratios in the $F_{1}$ progeny were scored until the final emergence of adults occurred. If there is a substantial difference in the segregation rate of the $M$-carrying sperm or in the viability of the male progeny between the males of $\mathrm{A}^{\mathrm{M}} / \mathrm{A}$ and $X / Y$, then the difference should appear between the sex ratios in their progeny. Such a difference would cause a dynamic state in plural male heterogametic systems. 
Table 2. Male genotypes observed in the sample from Yumenoshima in 1981

\begin{tabular}{|c|c|}
\hline $\begin{array}{c}\text { Male } \\
\text { genotypes }\end{array}$ & $\begin{array}{l}\text { No. of flies } \\
\text { observed }\end{array}$ \\
\hline II $/ \mathrm{II} ; \mathrm{III}{ }^{\mathrm{M}} / \mathrm{III} ; \quad X / X$ & 13 \\
\hline II $/ \mathrm{II} ; \mathrm{III} / \mathrm{III} ; \quad X / Y$ & 4 \\
\hline $\mathrm{II}^{\mathrm{M}} / \mathrm{II} ; \mathrm{III}{ }^{\mathrm{M}} / \mathrm{III} ; \quad X / Y$ & 1 \\
\hline II $/ \mathrm{II} ; \mathrm{III}{ }^{\mathrm{M}} / \mathrm{III} ; \quad Y / Y$ & 3 \\
\hline II $/ \mathrm{II} ; \mathrm{III}{ }^{\mathrm{M}} / \mathrm{III}^{\mathrm{M}} ; X / X$ & 11 \\
\hline $\mathrm{II}^{\mathrm{M}} / \mathrm{II} ; \mathrm{III}^{\mathrm{M}} / \mathrm{III}^{\mathrm{M}} ; X / Y$ & 7 \\
\hline II $/ \mathrm{II} ; \mathrm{III}{ }^{\mathrm{M}} / \mathrm{III}{ }^{\mathrm{M}} ; Y / Y$ & 1 \\
\hline Total & 40 \\
\hline
\end{tabular}

Table 3. The frequency of male progeny from the matings of single $M /+$ males to females carrying no sex factors

\begin{tabular}{lcc}
\hline & \multicolumn{2}{c}{ Genotype of male parent } \\
\cline { 2 - 3 } & III ${ }^{\mathrm{M}} / \mathrm{III}$ & $X / Y$ \\
\hline $\begin{array}{l}\text { No. of parental } \\
\text { males tested* }\end{array}$ & 320 & 405 \\
$\begin{array}{l}\text { Mean frequency of } \\
\text { male progeny } \pm \text { s.d. }\end{array}$ & $0.50 \pm 0.04$ & $0.50 \pm 0.05$ \\
$\begin{array}{l}\text { Range in the } \\
\text { frequencies } \\
\text { of male progeny }\end{array}$ & $0.42-0.61$ & $0.34-0.61$ \\
\hline * Only lines which produced more than 100 \\
offspring were used for calculation.
\end{tabular}

Based on this expectation, the $F_{1}$ sex ratios were compared between the offspring of $\mathrm{III} / \mathrm{M} / \mathrm{III}$ and $X / Y$ males. Lines which produced more than 100 offspring were used for the analysis. The number of lines tested, and the mean with standard deviation, minimum and maximum of the frequencies of male progeny are shown in Table 3. The mean frequencies \pm s.d. of the male progeny sired by the III ${ }^{\mathrm{M}} / \mathrm{III}$ and $X / Y$ parents were $0.50 \pm 0.04$ and $0.50 \pm 0.05$, respectively. Neither value was significantly different. The mechanism that might affect the dynamics in the most predominant male determinants in the fly population in Japan remains unknown.

\section{DISCUSSION}

The present study demonstrated a significant latitudinal cline in the fraction of the $Y\left(\right.$ or $\left.\mathrm{A}^{\mathrm{M}}\right)$ chromosome and a sporadic distribution of the $F /+$ females. The preserved pattern of the standard $X-Y$ system in northern populations of Japan is common to populations in continental Europe (Franco et al., 1982) and the British Isles (Denholm et al., 1985). Moreover, broadly ranging variations in the fraction of $Y$ (or $\mathrm{A}^{\mathrm{M}}$ ) and the frequency of the $F /+$ female, which is observed in populations in Japan, are similar to the results for populations in Europe (Franco et al., 1982; Denholm et al., 1985).

It is difficult to say whether autosomal $M$ and $F$ factors are long established ones or not, by the present geographic survey itself. Stable colonies of the housefiy in Japan have become much dispersed, and are localized in spots of livestock-breeding farms and large-scale dumps, in accordance with changes in ways of farming and living. Such a colony structure may cause genetic isolation among recent local populations of the housefly and broadly ranging variations in sex-determining genotypes. If so, the genetic structure for definitely long established polymorphims should also greatly differ among different populations. 
Agatsuma and Takeuchi (1978) studied an isozyme polymorphism for the $L D H$ $B$ locus. They examined the gene frequencies in 15 populations from Hokkaido to Kyushu. A significant latitudinal cline was demonstrated in the frequency of the most predominant allele, $B^{1.60}$; ranging between 0.52 and 0.92 with the average ( \pm s.d.) of $0.69( \pm 0.11)$. This variation seems quite moderate as compared with the variations of the fractions of $Y$ and III $^{\mathrm{M}}$ (Fig. 2) and the frequency of the $F /+$ female (Fig. 1). The geographic variation of the $L D H$ gene frequency indicated that these populations have not been subjected to much genetic drift through population subdivision. On the other hand, the ranges of the fractions of $Y$ and III ${ }^{\mathrm{M}}$ were $0.0-0.91$ and $0.09-1.0$, respectively, and the range of the $F /+$ female frequency was 0.0-0.99 (Table 1). Even without including the data of Hachijo, which is an isolated island, these ranges are not greatly narrowed. On the basis of the LDH polymorphism, large geographic variations in sex determinants might suggest that a relatively small number of generations has passed for autosomal sex-determining factors since their invasion into populations taking the standard sex-determining mechanism. This idea especially explains the sporadic distribution of the $F /+$ females.

A study of sex-determining system about 25 years ago (Hiroyoshi, 1964) gives a more direct evidence for transition in this system. Of 11 samples collected from Hokkaido to Kyushu, 9 of them included only $Y$ chromosome as the carrier of the $M$, and 2 samples contained both the $Y$ and $\mathrm{III}^{\mathrm{M}}$ chromosomes. The fact that no male with plural $M$ factors was included indicates a very low frequency, if any at all, of the $F /+$ female in the populations. On the contrary, of the 21 male samples examined by us and by Tsukamoto et al. (1980), all included the III ${ }^{\mathrm{M}}$ (Fig. 2) and 11 showed males with plural $M$ factors (Fig. 1). Although the number of tested males was not clearly stated in Hiroyoshi (1964), a great difference in sex determinants can be deduced from comparison of the populations in the 1960 's and the 1980 's.

In conclusion, the comparison of the results of a sex-determining system survey in the 1960 's and of an isozyme polymorphism study with the results of our present study suggests that the broadly ranging geographical variation in the multifactorial sex-determining system in housefly populations in Japan reflects a transient state caused by recent invasions of autosomal sex-determining factors. In an accompanying paper (Tomita and Wada, 1989), we will give further evidence for the recent invasion of the most predominant type of $\mathrm{A}^{\mathrm{M}}$ into a local population in Japan, based on linkage disequilibrium between the $M$ and an isozyme ioci.

At present, no reasonable mechanism for possible changes in the housefly sex-determining system can be shown, though some suggestions of the mechanism and their possibilities are the following. (i) Neither the meiotic drive which produces III $^{\mathrm{M}}$-carrying sperms in excess, nor viability selection which favors III ${ }^{\mathrm{M}} / \mathrm{III}$ males, was indicated in the present study. (ii) Mapping of several autosomal $M$ factors in each linkage group using recombination in the $F /+$ female 
resulted in no distinctive difference among locations (Inoue et al., 1983; Inoue and Hiroyoshi, 1984; Inoue et al., 1986). Thus, whether or not the $M$ factors located in homologous autosomes of independent origins are identical by descent remains unknown. (iii) The housefly is a nuisance and has been a target of insecticidal control. The original isolation of autosomal $M$ factors coincided with the appearance of insecticide resistance in the population. However, it is difficult to develop any simple hypothesis relating these two phenomena. Selection for such $A^{\mathrm{M}}$ as a supergene complex with insecticide resistant mutations is a possible mechanism by which its frequency in the population might be increased without the $F$ factor, due to holandric inheritance of the $M$ factor and rare recombination in males, but this idea is greatly dependent on chance. (iv) Inoue and Hiroyoshi $(1982,1986)$ reported that the $F /+$ female produced intersex flies only in progeny carrying neither $F$ nor $M$ by the maternal effect of the $F$ factor when the progeny was reared under a high temperature condition. This effect of the $F$ might have affected the dynamics in $F$ locus polymorphism, indirectly selecting for the $F /+$ female.

We thank Drs. T. Mukai (Kyushu University) and T. Hiroyoshi (Osaka University) for their encouragement throughout this work, and Dr. T. Shono (National Institute of Health) for kindly reading the manuscript. This work was partly supported by a grant (No. 61480141) from the Ministry of Education, Science and Culture of Japan.

\section{REFERENCES}

Agatsuma, T. and TakeuchI, T. (1978) Genetic polymorphism of LDH isozymes in the housefly, Musca domestica. II. Geographic cline observed in natural populations. Jpn. J. Genet. 53, 317325.

Denholm, U., Franco, M. G., Rubini, P. G. and Vecchi, M. (1983) Identification of a male determinant on the $X$ chromosome of the housely (Musca domestica L.) population in South-East England. Genet. Res. 42, 311-322.

Denholm, I., Franco, M. G., RubinI, P. G. and Vecchi, M. (1985) Geographical variation in house-fly (Musca domestica L.): sex determinants within the British Isles. Genet. Res. Camb. 47, 19-27.

Franco, M. G., RUbini, P. G. and Vecchi, M. (1982) Sex-determinants and their distribution in various populations of Musca domestica L. of Western Europe. Genet. Res. 40, 279-293.

Hiroyoshi, T. (1964) Sex-limited inheritance and abnormal sex ratio in strains of the housefly. Genetics 50, 373-385.

HIRoYoSHI, T. and FUKUMORI, Y. (1977) On the III $^{\mathrm{M}}$-type houseflies frequently appeared in Japan. Jpn. J. Genet. 52, 443 (in Japanese).

HIROYOSHI, T. and FUKUMORI, Y. (1978) On the sex-determination in wild populations of the housefly. Jpn. J. Genet. 53, 420-421 (in Japanese).

INoUE, H. and HiroyoshI, T. (1982) A new sex-transforming gene of the housefly. Jpn. J. Genet. 57, 673 (in Japanese).

INoUe, H., FUKUMORI, Y. and HIRoYoshi, T. (1983) Mapping of autosomal male-determining factors of the housefly, Musca domestica L., by means of sex-reversal. Jpn. J. Genet. 58, 451-461.

INoUE, H. and HIRoYoshI, T. (1984) Mapping of autosomal male-determining factors of the housefly, 
Musca domestica L., by using a female-determining factor. Jpn. J. Genet. 59, 453-464.

Inoue, H. and HiRoYoshi, T. (1986) Sex-transformation caused by maternal effect of a femaledetermining factors, $F$, of the housefly. Jpn. J. Genet. 61, 584 (in Japanese).

INOUE, H., TOMiTA, T. and HIRoYoshI, T. (1986) Location of fourth chromosomal male-determining factors of the housefly, Musca domestica. Jpn. J. Genet. 61, 119-126.

KEUNEKE, W. (1924) Üoer die Spermatogenese einiger Dipteren. Zeitschrift für Zelleforschung und Gewebelehere 1, 257-412.

McDonald, I. C., Evenson, P., Nickel, C. A. and Johnson, O. A. (1978) House fly genetics: isolation of a female determining factor on chromosome 4. Ann. Entomol. Soc. Am. 71, 692-694.

MeTz, C. W. (1916) Chromosome studies on the Diptera, II. The paired association of chromosomes in the Diptera, and its significance. J. Expt. Zool. 21, no. 2, 213-279.

PerJe, A. M. (1948) Studies on the spermatogenesis in Musca domestica. Hereditas 34, 209-232.

Rubini, P. G. and Palenzona, D. (1967) Response to selection for high number of heterochromosomes in Musca domestica L. Genet. Res. 21, 101-110.

Stevens, N. M. (1908) A study of the germ cells of certain Diptera with reference to the heterochromosomes and phenomenon of synapsis. J. Exp. Zool. 94, 153-162.

Tomita, T. and WADA, Y. (1989) Migration and linkage disequilibrium in local populations of the housefly (Musca domestica) in Japan. Jpn. J. Genet. 64, 383-389.

TsuKamoto, M., ShoNo, T. and HoRIo, M. (1980) Autosomal sex-determining system of the housefly: Discovery of the first-chromosomal male factor in Kitakyushu, Japan. J. Univ. Occupational and Environmental Health 2, 235-252.

WAGONER,. D. R. (1969) Presence of male determining factor found on three autosomes in the housefly, Musca domestica. Nature 233, 187-188.

WAGONER, D. R. and Johnson, O. A. (1974) Strains of house flies producing only males. Ann. Entomol. Soc. Amer. 67, 553-554. 